\title{
APRENDIZAJE, DESARROLLO Y EVALUACIÓN EN CONTEXTOS ESCOLARES: CONSIDERACIONES TEÓRICAS Y PRÁCTICAS DESDE EL ENFOQUE HISTÓRICOCULTURAL
}

LEARNING, DEVELOPMENT AND ASSESSMENT IN EDUCATIONAL CONTEXTS: THEORETICAL, METHODOLOGICAL ANDA PRACTICAL CONSIDERATIONS FROM A CULTURAL-HISTORICAL PERSPECTIVE

Volumen 11, Número 1

pp. 1-36

Este número se publicó el 30 de abril de 2011

Wanda Rodríguez Arocho

La revista está indexada en los directorios:

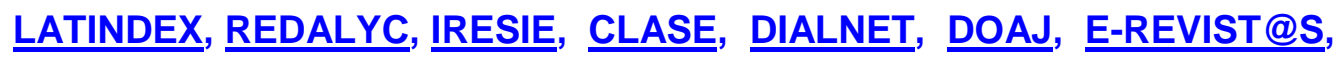

La revista está incluida en los sitios:

REDIE, RINACE, OEI, MAESTROTECA, PREAL, HUASCARAN, CLASCO 


\title{
APRENDIZAJE, DESARROLLO Y EVALUACIÓN EN CONTEXTOS ESCOLARES: CONSIDERACIONES TEÓRICAS Y PRÁCTICAS DESDE EL ENFOQUE HISTÓRICOCULTURAL
}

\author{
LEARNING, DEVELOPMENT AND ASSESSMENT IN EDUCATIONAL CONTEXTS: \\ THEORETICAL, METHODOLOGICAL ANDA PRACTICAL CONSIDERATIONS FROM A \\ CULTURAL-HISTORICAL PERSPECTIVE
}

\begin{abstract}
Wanda Rodríguez Arocho ${ }^{1}$
Resumen: En este ensayo se analiza la relación entre aprendizaje, desarrollo y evaluación en contextos educativos desde el enfoque históricocultural. Como método de trabajo se ha utilizado el análisis de discurso de las formulaciones teóricas originales del enfoque y una revisión de sus desarrollos actuales en investigaciones e intervenciones psicoeducativas. En el análisis, se identifican y se examinan conceptos centrales de este enfoque, paradójicamente poco discutidos, como es el caso del concepto unidad de análisis. Nuestro estudio revela una estrecha relación entre los procesos de aprendizaje (apropiación y dominio de artefactos y signos culturales), desarrollo (transformaciones en la conciencia y la subjetividad enraizadas en dinámicas históricoculturales y socioinstitucionales), y evaluación (herramienta que puede incidir sobre ambos procesos). Se presentan y discuten algunos ejemplos concretos de prácticas de evaluación que pueden promover el aprendizaje y el desarrollo. Se concluye que, desde el enfoque históricocultural, aprendizaje, desarrollo y evaluación, constituyen una unidad indivisible con serias implicaciones para las prácticas docentes y las investigaciones psicoeducativas. Estas implicaciones obligan a realizar una mirada crítica de las formas tradicionales de pensar y hacer evaluación en contextos educativos.
\end{abstract}

Palabras clave: APRENDIZAJE, DESARROLLO, EVALUACIÓN, ENFOQUE SOCIOCULTURAL, PEDAGOGÍA, VYGOTSKI

\begin{abstract}
This essay analyzes the relationship between learning, development and assessment in educational contexts from a cultural-historical perspective. The methodological approach to analysis includes discourse analysis of the original theoretical formulations and a review of current developments in psychoeducational research and intervention. The analysis identifies and examines central concepts in the cultural-historical perspective, paradoxically not frequently discussed, as is the case with the concept of unit of analysis. Our analysis reveals a close relationship of interdependency between learning processes (appropriation and mastering of cultural artifacts and signs), development (transformations in consciousness and subjectivity rooted in culturalhistorical and socio-institutional dynamics), and assessment (tool that could impact both learning and development). Some concrete examples of assessment practices to promote learning and development are presented and discussed. We conclude that from a cultural-historical perspective learning, development and assessment, constitute an indivisible unit with serious implications for teaching practices and psychoeducational evaluations. These implications urge to a critical look at the traditional ways of thinking and doing evaluation in educational contexts.
\end{abstract}

Key words: LEARNING, DEVELOPMENT, ASSESSMENT, SOCIOCULTURAL APPROACH, PEDAGOGY, VYGOTSKY

\footnotetext{
Catedrática del Departamento de Psicología de la Universidad de Puerto Rico, Recinto de Río Piedras. Dirección electrónica: wcrodriguez@uprrp.edu.com
}

Artículo recibido: 26 de octubre, 2010

Aprobado: 7 de marzo, 2011 


\section{CONSIDERACIONES TEÓRICO-METODOLÓGICAS}

La experiencia de largos años de trabajo en actividades de formación a educadores y educadoras, así como en el estudio de los modelos y prácticas de formación existentes, me han llevado al convencimiento de que tanto en la formación de entrada como en la educación continua, que luego sigue en los centros de trabajo, domina el interés por las técnicas y estrategias. No vería ningún problema en ese muy legítimo interés si no fuera porque, generalmente, lo he visto acompañado de devaluación, cuando no un rechazo, del saber teórico. Se le otorga a ese saber teórico una menor utilidad que al saber práctico de pronta aplicación.

En consecuencia, la demanda, muchas veces gestada por la necesidad de resolver problemas en la realidad cotidiana de las escuelas, es por una prescripción, por una estrategia para la enseñanza y la evaluación que ayude a resolver el problema que se vive en el aula, que unas veces se llama problema de disciplina, otras de motivación y otras de aprendizaje; en este caso, el nombre que le damos a ese problema no es tan importante como lo que devela; lo que devela es el hecho de que no se nos ha preparado en los programas de formación para entender que no hay una técnica o estrategia que se sostenga al margen de un marco conceptual y que no hay un marco conceptual que pueda construirse al margen de premisas filosóficas y de las formas de pensar que derivan de ellas. No obstante, tomar conciencia de este hecho es fundamental para una práctica docente reflexiva (Rodríguez Arocho, 2010). En el convencimiento de que, como argumentó Kurt Lewin (1991), no hay nada más práctico que una buena teoría, pasamos a examinar lo que aporta el enfoque históricocultural al tema que nos ocupa.

Una de las principales contribuciones teóricas y metodológicas del enfoque históricocultural al estudio del desarrollo humano es la noción de unidad de análisis (van der Veer, 2001). Luego de un profundo examen de los objetos y métodos de estudio de la psicología de su época, Vygotski (1927/1991) llegó a la conclusión de que ésta tendía a fragmentar el pensamiento, el lenguaje, las emociones, y otras funciones complejas implicadas en la actividad humana, en sus elementos o componentes constituyentes. Argumentó que esto constituía una seria limitación para captar y entender las complejas dinámicas que dan forma a esos procesos y explican sus cambios en el curso del desarrollo (Rodríguez Arocho, 2007a, 2008).

Desde las reflexiones de Vygotski en su trabajo El significado histórico de la crisis de la psicología: Una investigación metodológica, fechado en 1927, hasta los planteamientos en Volumen 11, Número 1, Año 2011, ISSN 1409-4703 
su obra póstuma Pensamiento y lenguaje, fechada en 1934, encontramos en las formulaciones originales del enfoque históricocultural contundentes argumentaciones en contra de la fragmentación y del reduccionismo que han marcado el estudio de lo humano en la aplicación irreflexiva del modelo de las ciencias naturales a las ciencias sociales, particularmente en la psicología (Smith, Harré \& Langenhove, 1995ab) y en la educación (Morin, 1999).

En las teorías de desarrollo humano esta marca se observa en lo que del Río y Álvarez (1997) identifican como la reducción a lo racional (dejando al margen lo afectivo), la reducción lo individual (dejando al margen lo social, lo interpersonal), la reducción a lo interno (dejando al margen lo externo, la realidad objetiva), y la reducción a lo innato (dejando al margen lo cultural). Estos reduccionismos están tan instalados en las formas tradicionales de hacer ciencia que a veces no reconocemos su fuerza e influencia, aún en investigaciones que dicen suscribir el modelo históricocultural. Con mucha lucidez, Luis Moll (1997) y Ricardo Baquero $(2007,2009)$ nos advierten de ello al señalar que se han reducido conceptos como el de la zona de desarrollo próximo al ámbito de lo interpersonal inmediato y de lo microsocial. Ambos autores plantean que esto termina por limitar nuestra comprensión de las dinámicas sociales mayores donde se efectúan y significan las acciones humanas. Para comprender estos planteamientos, muy pertinentes al tema de la evaluación del desarrollo y el aprendizaje, es necesario comprender el alcance de la propuesta históricocultural. El concepto de unidad de análisis juega un rol central en la misma.

Vygotski propuso que, en lugar del análisis por elementos, la explicación del desarrollo humano (y del aprendizaje) debe buscarse en el análisis por unidades. Concibió la unidad como una categoría que abarca "todas las propiedades fundamentales características del conjunto y constituye una parte viva e indivisible de la totalidad" (1934/1993, p.19). A lo largo de su obra exploró varias unidades de análisis; para estudiar el comportamiento general propuso la actividad instrumental, para estudiar el pensamiento lingüístico (producto de la interacción entre pensamiento y lenguaje) propuso la palabra-significado como unidad de análisis, y para estudiar la integración de personalidad y medio ambiente propuso la vivencia. Es pertinente destacar que subrayó el imperativo de aproximarse al estudio de estas unidades como sistemas funcionales integrados interdependientes regidos por las leyes de la dialéctica. Muchos de los argumentos que utilizó, en su discusión de las limitaciones de los modelos reduccionistas, guardan una marcada similitud con lo que en la actualidad se ha llamado epistemología de la complejidad (D’Angelo, 2005; Fariñas León, 2005; Morin, 1999; 
Munné, 1997, 2004, 2005). Aunque esta epistemología se expresa actualmente en una variedad de teorías en campos de actividad intelectual muy diversos, comparten la idea de que es necesaria una mirada compleja para trascender la simplicidad y superar todo tipo de reduccionismo o elementalismo. Estas mismas ideas se encarnan en el concepto de unidad de análisis.

El tema del análisis por unidades fue reiteradamente enfatizado por Vygotski y es parte del conjunto de herramientas que ofrece el enfoque históricocultural. Este enfoque propone, como tesis central, que las funciones psíquicas superiores, como la atención voluntaria, la memoria lógica, el razonamiento, el ejercicio de la voluntad (autorregulación), la motivación y la afectividad, si bien se hacen posibles gracias a una dotación biológica resultado de la evolución de nuestra especie, están mediadas por la cultura (Vygotski, 1931a/1995). Estas funciones emergen en el curso del desarrollo humano individual como resultado de la mediación de herramientas y sistemas de representación en la actividad humana contenidos en la cultura. En el caso de la cría humana esta mediación se da en el curso de interacciones sociales, donde el lenguaje y otras formas de comunicación juegan un rol central. La apropiación y uso de estas formas de mediación, la constitución de la subjetividad y la conformación de la mente quedan unidas en el curso del desarrollo individual (Rodríguez Arocho, 2000a). El desarrollo cultural, por su parte, se entrelaza con el desarrollo individual en el sentido de que el surgimiento y uso, socialmente generalizado de nuevas tecnologías, conllevará transformaciones mentales (Rodríguez Arocho, 2002).

La siguiente cita de Silvia Scribner (1990) sintetiza, magistralmente, el enfoque históricocultural y la particular contribución de Vygotski:

La genialidad especial de Vygotski fue capturar el significado de lo social en las cosas tanto como en las personas. El mundo en que vivimos está humanizado, lleno de objetos materiales y simbólicos (signos, sistemas de conocimiento) que son culturalmente construidos, históricos en su origen y sociales en su contexto. Dado que todas las acciones humanas, incluidos actos y pensamientos, involucran la mediación de tales objetos ('herramientas y signos'), éstos son, sólo por eso, sociales en su esencia. Este es el caso no importa que los actos sean iniciados por un agentes solo o por un colectivo, que se ejecuten individualmente o junto a otros (p. 92, traducción de la autora).

Ante este planteamiento, la idea de unidad de análisis cobra su total sentido. Si se quieren entender las funciones psíquicas que nos diferencian de otras especies, hay que 
considerar las actividades que se realizan, los medios que utilizan y el contexto particular de la actividad. Hay que entender también cómo llegamos a relacionarnos con las actividades, con los medios y los contextos. Es la explicación de ese cómo la que otorga a la educación el rol central que ocupa la historia del desarrollo de las funciones psíquicas superiores.

\section{APLICACIÓN A LA COMPRENSIÓN DEL APRENDIZAJE Y DESARROLLO HUMANOS}

Lo planteado llevó a Jerome S. Bruner (1962) a sostener, en la introducción a la primera traducción al inglés de la obra Pensamiento y Lenguaje, que "la concepción de Vygotski del desarrollo es al mismo tiempo una teoría de la educación" (p.v); también es lo que lleva a Moll (1990) a sostener que

Vygotski no sólo consideraba que la educación es dominante en el desarrollo cognitivo sino que también es la quintaesencia de la actividad cultural. Es decir, que consideraba la capacidad de enseñar y de beneficiarse de la instrucción como un atributo fundamental de los seres humanos. (p.13, traducción nuestra).

La contribución de Vygotski a la educación podría resumirse señalando que colocó el proceso de enseñanza-aprendizaje en el centro de su concepción del origen y desarrollo de la mente. No deja lugar a dudas esta cita suya:

...Cuando en realidad la educación, entendida en el más amplio sentido de la palabra, debe ser el eje fundamental alrededor del cual se estructura todo el desarrollo de la personalidad del niño. Una línea dada de desarrollo debe ser entendida como la consecuencia lógica necesaria de una línea de educación. (Vygotski, 1931/1997, p.325)

Luego de expresar este pensamiento, Vygotski hace dos aclaraciones importantes; la primera es que el estudio de las prácticas educativas debe informar el estudio del desarrollo, aunque podríamos argumentar que se observa lo contrario cuando se aplican, irreflexivamente, las teorías de desarrollo producidas en la psicología a la práctica educativa; la segunda aclaración es que la educación rebasa las prácticas de crianza y los aprendizajes en la escuela, es un proceso distribuido en la amplitud y variedad de las prácticas culturales; en la actualidad esas prácticas incluyen los usos de las Tecnologías de la Información y la Comunicación (TIC). 
Con base en lo expuesto, es posible llegar a la conclusión de que en el enfoque históricocultural, la educación, que incluye procesos de enseñaza-aprendizaje, se considera la principal promotora del desarrollo humano. Al margen de la educación, que facilita la apropiación de la cultura, el desarrollo propiamente humano es imposible; la alfabetización y la escolarización permitirán un tipo de desarrollo particular. Como documentó Luria (1976), estas actividades viabilizan transformaciones en la atención y la percepción, la generalización y la abstracción, la deducción y la inferencia, el razonamiento y la solución de problemas, la imaginación, la reflexión, el autoanálisis y la toma de conciencia de los propios pensamientos, motivos y afectos. Mediante la alfabetización y la escolarización aprendemos el uso y el dominio de tecnologías de la representación y la comunicación que nos equipará de una manera particular para enfrentar el mundo (Kozulin, 2000).

Esto quiere decir que a la escuela no vamos sólo a aprender los contenidos de las materias que están en el currículo; vamos, sobre todo, a desarrollar por vía del aprendizaje, formas particulares de pensar y actuar; no obstante, a veces no tomamos en cuenta que los contextos donde pensamos y actuamos se caracterizan por una notable diversidad. Nos aproximamos a los niños y niñas en las escuelas bajo unos supuestos de uniformidad y homogeneidad que son falsos; ni siquiera nos planteamos la diversidad de formas de lo escolar que la actualidad históricocultural implica (Baquero, Diker \& Frigerio, 2007).

De lo anterior se desprende que, desde el enfoque históricocultural, el desarrollo no se ve como el desdoblamiento progresivo de capacidades innatas o como el paso gradual lineal de una etapa a otra condicionado por el ambiente externo, sino como un proceso dinámico, interactivo y, sobre todo, dialéctico; esto quiere decir que el proceso se caracterizará por tensiones, contradicciones y complejas redes de interacción, donde lo externo y lo interno, lo objetivo y lo subjetivo, lo individual y lo social se entrelazan para hacerse inseparables, cuando no indistinguibles. En esta concepción de desarrollo, el aprendizaje juega un rol central, porque, como ha señalado Luis Moll (1990), es considerado la quintaesencia de la mediación. Como se ha argumentado reiteradamente en el enfoque históricocultural, desde su formulación original hasta el presente sobre la actividad, mediada instrumental y simbólicamente, se construye nuestra condición humana (Daniels, 2001; Luria, 1976; Roggof, 2003; Valsiner, 2007; Vygotski, 1931/1995; Wertsch, 1991).

Procede tener en cuenta que el desarrollo y el aprendizaje siempre ocurrirán en situaciones concretas que constituyen no un mero escenario para su ocurrencia, sino un contexto-ambiente que es inseparable del sujeto que lo vivencia en su particular situación 
social de desarrollo. Comprender el lugar que ocupan las nociones de situación social de desarrollo y vivencia en el enfoque históricocultural requiere entender que se trata de una forma diferente de mirar la relación entre la persona y su medio ambiente de la que ha caracterizado el acercamiento a esa relación en la psicología tradicional.

En la psicología tradicional, el ambiente se entiende como algo externo al sujeto, cuyos indicadores pueden ser identificados con precisión para determinar el peso de su impacto o influencia en el desarrollo; en los contextos académicos, por ejemplo, buscamos conocer el nivel socioeconómico donde ubicamos a la persona que educamos, porque partimos del supuesto de que dicho nivel determina el acceso a recursos indispensables para lo que hemos definido como un buen desarrollo. Estos recursos pueden ir desde una buena nutrición y condiciones de higiene hasta el acceso a equipo y materiales. De igual modo, se considera la influencia de la familia, tomando en cuenta si se proviene de un hogar conformado de una manera particular. Otras veces, nos enfocamos en las características del alumno, que las vemos como propiedades fijas que le definen, como su cociente intelectual, sus niveles de atención, sus destrezas motoras. Estos y muchos otros indicadores de las condiciones de desarrollo son constantemente utilizados como "variables independientes" en investigaciones en psicología y educación para explicar "la variable dependiente", en este caso, el rendimiento académico o el aprendizaje. Aún diseños cualitativos, que sustituyen esta terminología experimental, no rebasan el esquema del medio como algo externo que influye, condiciona o determina el desarrollo; no se ven las condiciones y características mencionadas como multideterminadas y relacionadas. En el enfoque históricocultural encontramos un llamado a superar estas limitaciones.

Para Vygotski, el estudio teórico y práctico del desarrollo enfrenta una de sus mayores dificultades cuando el entorno se considera como algo externo, cuando se le mira y entiende como el escenario o las circunstancias de su desarrollo, como un conjunto de condiciones objetivas independientes (Vygotski, 1932/1996). Es pertinente señalar que para Vygotski éste no era sólo un problema teórico; su trabajo clínico con niños con diversos problemas físicos (como ceguera y sordera) y mentales (como retardación mental y rezago en el desarrollo) y variados contextos de vida (como limitaciones materiales, pobreza extrema y abandono), lo llevó a percatarse de la singular relación de la cría humana con su medio ambiente (Vygotski, 1997). Tomó conciencia de que esa relación es dinámica y cambiante y no puede aprehenderse considerando los indicadores objetivos, porque éstos están sujetos a la forma en cómo son experimentados por cada sujeto en su particular momento del 
desarrollo. La comprensión del papel del medio en el desarrollo demanda no sólo la consideración de los indicadores externos y sus cambios, sino de los cambios que ocurren en la persona como resultado de su actividad en ese medio, actividad que está históricamente situada y es mediada por la cultura en interacciones sociales.

Fue para designar esa dinámica de los procesos internos del desarrollo con las condiciones externas del mismo que Vygotski acuñó el término "situación social del desarrollo" (Vygotski, 1933/1996). Esta situación cambia en la medida en que las funciones mentales se reorganizan y reestructuran en el curso del desarrollo; en consecuencia, la evaluación del aprendizaje y del desarrollo estaría sesgada e incompleta si no se toman en consideración la situación social del desarrollo y las vivencias.

Desafortunadamente, la evaluación educativa, por tradición, se ha enfocado en indicadores cuantitativos que se presumen objetivos y que se supone ofrecen una medida, si no exacta, al menos puntual, de las características del aprendiz que son objeto de medición. La medida obtenida se utilizará para compararle con otros aprendices que se encuentran en la misma situación de desarrollo o aprendizaje. Frente a este tipo de evaluación, Vygotski abogará por lo que llamó evaluación diagnóstica. Esta evaluación se asienta en la teoría general de desarrollo antes expuesta y, a partir de los principios explicativos de ésta, busca penetrar la dinámica interna causal y establecer las conexiones genéticas que definen el proceso de desarrollo mental. Estos dos modos de entender la evaluación crean un dilema que Arias Beatón (2001) describe así: "La evaluación y el diagnóstico psicológico y educativo se debaten entre un enfoque cuantitativista, clasificador, descriptivo y estigmatizante y otro enfoque formativo, explicativo, y correctivo encaminado a eliminar las dificultades que se detecten en el proceso evaluativo" (p. 120). La evaluación diagnóstica, entendida en estos términos, busca conocimiento para promover aprendizaje y, en consecuencia, desarrollo; por ello, sus técnicas y estrategias, como la de cualquier proceso de investigación que busque explicaciones más que descripciones, deberán responder a lo que Vygotski denominó el método genético.

Vygotski propondrá el método genético como alternativa para el abordaje de funciones psicológicas complejas; este método combina el análisis clínico con la realización de tareas que demandan actividad cognitivo-afectiva. Vygotski señaló como las características definitorias de este método:

el análisis del proceso y no del objeto, que ponga de manifiesto el nexo dinámicocausal efectivo y su relación en lugar de indicios externos que disgregan el proceso; 
por consiguiente, de un análisis explicativo y no descriptivo que vuelva a su punto de partida y reestablezca todos los procesos de desarrollo de una forma que en su estado actual es un fósil psicológico. (Vygotski, 1931a/1995, pp. 105-106). ¿Qué implican estas características en la evaluación psicoeducativa?

Con respecto al análisis de proceso versus análisis del objeto, el problema que busca enfrenarse es que, al enfocarse en el resultado o producto de actividad, se pierden su dimensión dinámica y las particularidades de ésta; por ejemplo, en la evaluación de la capacidad intelectual o cognitiva puede utilizarse como indicador de ésta el resultado en una prueba estandarizada de inteligencia, porque se entiende que la medida cumple con criterios de validez y confiabilidad altamente estimados en la evaluación tradicional; pero ese indicador nos dirá poco con respecto a los procesos cognitivos y afectivos particulares que producen la respuesta que se ha definido como inteligente. Poco sabremos con respecto a la forma en que la persona particular que está siendo evaluada atiende, recuerda, procesa información, planifica y soluciona problemas, sobre cuál es su situación social de desarrollo y cómo su vivencia se expresa en las respuestas. Más aún, no reconocemos que el instrumento en sí mismo encierra una concepción del concepto inteligencia que tenderá a privilegiar determinadas formas de solucionar problemas, los cuales muchas veces están distantes de la realidad cotidiana del sujeto evaluado. Este tipo de práctica puede encubrir variabilidad en procesos específicos bajo un indicador que aglutina todo como si se tratara de lo mismo; sin embargo, Vygtoski hizo una propuesta que nos lleva a repensar las formas de aproximarnos a la ejecución intelectual, al igual que a muchos otros constructos teóricos. Sobre el particular dice:

Hasta ahora, en el análisis psicológico el proceso analizado casi siempre era un cierto objeto. La formación psíquica se entendía como una cierta forma estable y sólida; la tarea de análisis se reducía a descomponerla en partes aisladas. Por este motivo ha prevalecido hasta la fecha en este análisis psicológico la lógica de los cuerpos sólidos. K. Koffa dice que el proceso psíquico se estudiaba y analizaba como un mosaico de partes sólidas e invariantes.... El análisis del objeto debe contraponerse al análisis del proceso, el cual, de hecho, se reduce al despliegue dinámico de los momentos importantes que constituyen la tendencia histórica del proceso dado... No es la psicología experimental, sino la genética la que nos lleva a esa nueva concepción del análisis. (p. 100) 
Además de considerar la dinámica de los sistemas que estudia, la evaluación psicoeducativa debe enfocarse en el análisis explicativo más que en el análisis descriptivo, esta tampoco es una tarea simple. Según indica Vygotski:

El paso del concepto descriptivo al explicativo no se realiza por medio de la simple sustitución de unos conceptos por otros... El análisis fenomenológico o descriptivo toma el fenómeno tal cual es externamente y supone con toda ingenuidad que su aspecto exterior o la apariencia del objeto coinciden con el nexo real, dinámico-causal que constituye su base. El análisis genético-condicional se inicia poniendo de manifiesto las relaciones efectivas que se ocultan tras la apariencia externa de algún proceso. El último análisis se interesa por el surgimiento y la desaparición, las causas y las condiciones y por todos los vínculos reales que constituyen los fundamentos de algún fenómeno. (pp. 101-103)

Con este planteamiento, Vygotski llama la atención a no confundir la causalidad lineal con la explicación causal; la casualidad lineal busca relaciones de causa y efecto, cuyo criterio de verdad es la frecuencia y fuerza de su asociación temporal visible; la explicación causal busca trascender el límite de lo observable al abordar motivos, intenciones y vivencias que dan sentido a lo observable. Volviendo al ejemplo de las pruebas estandarizadas de inteligencia, se trataría de ir más allá de la información que ofrece el dato para entender las condiciones que pueden incidir sobre ese dato; no obstante, los protocolos de evaluación, que persiguen la uniformidad y la normalización, no admiten desviación. Las preguntas de por qué y cómo se realizan las acciones inteligentes quedan sin responder.

En cuanto al análisis dinámico, no fosilizado, Vygotski apuntó:

$\mathrm{Y}$, finalmente, nuestra tercera tesis fundamental consiste en lo siguiente: en psicología solemos encontrar con bastante frecuencia procesos ya fosilizados, es decir, por haber tenido un largo periodo de desarrollo histórico, se han petrificado. La fosilización de la conducta se manifiesta sobre todo en los llamados procesos psíquicos automatizados o mecanizados. Son procesos que por su largo funcionamiento se han repetido millones de veces y, debido a ello, se automatizan, pierden su aspecto primitivo y su apariencia externa no revela su naturaleza interior; diríase que pierden todos los indicios de su origen. Gracias a esa automatización su análisis psicológico resulta muy difícil... Por consiguiente, no debemos interesarnos en el resultado acabado, ni buscar el balance o producto del desarrollo, sino el propio proceso de aparición o el establecimiento de la forma superior tomada en su aspecto vivo. Para ello, el 
investigador debe transformar frecuentemente la índole automática, mecanizada y fosilizada de la forma que nos interesa, a sus momentos iniciales para tener la posibilidad de observar el proceso de su nacimiento. En ello, tal como ya dijimos, radica, la misión del análisis dinámico. (p.105)

Las características del método propuesto por Vygotski subrayan la dimensión histórica de las funciones psicológicas y, en consecuencia, se enfocan en el origen, formación y transformación de estos procesos. Cuando aplicamos medidas de, o realizamos tareas para, evaluar atención, memoria, razonamiento o la capacidad de solución de problemas, por ejemplo, debemos evitar examinar estos procesos como completos y acabados. Cada uno de estos procesos sufre transformaciones importantes como sistema y en su vinculación a otros sistemas de la vida psíquica; más aún, la evaluación debe descubrir los puntos de inflexión de estos procesos para ayudar en su transformación.

\section{EL LUGAR DE EVALUACIÓN EDUCATIVA EN EL APRENDIZAJE Y EL DESARROLLO HUMANOS}

Las personas familiarizadas con las discusiones en el área temática de evaluación psicológica y evaluación educativa habrán reconocido en estos planteamientos los argumentos contra la psicometría tradicional y el apoyo a algunos de los principales modelos de evaluación dinámica y remediación cognitiva (Kozulin \& Gindis, 2007; Lidz \& Gindis, 2003).

En esta literatura hay continuas referencias al concepto por el que Vygotski es más conocido, la zona de desarrollo próximo (Rodríguez Arocho, 1998). No podemos terminar este apartado de consideraciones teóricas sin hacer algunos señalamientos críticos sobre el manejo de este concepto. El propósito de estos señalamientos es promover la reflexión crítica para que el concepto se ubique en el sistema teórico al que pertenece y no se le trate de manera aislada e independiente, lo que parece haber ocurrido con frecuencia. Así lo expresa Gordon Wells (1999), uno de los autores contemporáneos que se ha distinguido por elaboraciones de las aplicaciones del enfoque histórico cultural a la educación. Este autor comunica su preocupación por el tratamiento del concepto de zona de desarrollo próximo en la siguiente cita: “...ciertamente, es el único aspecto de la teoría de genética del desarrollo humano que la mayoría de los educadores ha escuchado $y$, como consecuencia, es frecuentemente citada para justificar formas de enseñanza que parecen considerablemente incompatibles con la teoría como un todo" (Wells, 1999, p.313, en traducción nuestra).

Volumen 11, Número 1, Año 2011, ISSN 1409-4703 
La referencia implícita de Wells en esta cita es a un amplio cuerpo de literatura sobre intervenciones educativas y evaluaciones que dicen desarrollarse a partir del concepto de zona de desarrollo próximo que él mismo discute en el referido texto. Este cuerpo abarca un amplio espectro que cubre desde su uso en la enseñanza de las más variadas materias (desde matemáticas e idiomas hasta música y educación moral), en diversos grupos de edad (desde preescolares hasta adultos), en diferentes grupos poblacionales (desde superdotados hasta personas con limitaciones variadas), pasando por la enseñanza de la lectura, la escritura y las nuevas tecnologías de la información y la comunicación (Chaklin, 2003; del Río y Álvarez, 2007). La mayoría de las intervenciones documentadas en la literatura siguen la consabida definición de la zona como la distancia entre lo que el aprendiz puede realizar solo y lo que puede realizar con la ayuda de un adulto o un par más capaz y testimonian el valor de uso de las intervenciones para facilitar el aprendizaje. Las intervenciones, por supuesto, subrayan el carácter flexible, modificable y desarrollable del aprendiz y demuestran los cambios en su zona de desarrollo próximo.

Sin dejar de reconocer que las mencionadas intervenciones nos ofrecen una herramienta más flexible para la evaluación del aprendizaje y del desarrollo, su uso descontextualizado del sistema teórico del que es parte implica el riesgo de un nuevo tipo de reduccionismo. Esto se observa, por ejemplo, en algunas intervenciones donde lo único que falta son indicadores cuantitativos del tamaño de la zona de desarrollo próximo y del efecto de la intervención. Así, la zona deja de entenderse como un espacio de interacción social, como contexto de intercambio, y pasa a entenderse como una propiedad del sujeto. Al examinar el concepto en el marco general de la teoría debe quedar claro que el potencial no es una propiedad del niño; más bien, como ha señalado Chaklin (2003) "es simplemente la indicación de la presencia de ciertas funciones en maduración, la que puede señalarse para intervenir significativamente" (p.43). Por lo tanto, quien significa y quien interviene es agente en la situación social de desarrollo que deberá mediar en las tensiones y contradicciones entre las capacidades actuales evidenciadas en las funciones psicológicas ya desarrolladas, en las necesidades y deseos que emergen de las vivencias, y en las demandas y posibilidades del ambiente concreto en que se vive. Es en la situación social de desarrollo, totalmente atravesada por las vivencias, donde la zona de desarrollo próximo cobra sentido.

Ante lo dicho, la zona no puede ser simplemente caracterizada como la distancia entre lo que se puede hacer independientemente y lo que se puede hacer con ayuda de otro. La siguiente cita de Chaklin sintetiza la complejidad que busca capturar el concepto: 
En suma, las principales características del análisis de la zona de desarrollo próximo son: (1) el niño como totalidad, (b) su estructura interna (relaciones entre funciones psicológicas) y (c) el desarrollo como cambio cualitativo en las relaciones estructurales, (d) que emergen por las acciones del niño en su situación social de desarrollo (reflejando lo que el niño percibe y lo que le interesa, donde (e) cada periodo de edad tiene su actividad orientadora/contradicción que organiza las acciones del niño (donde están operando intereses subjetivos) por medio de lo cual se desarrollan nuevas funciones. La zona de desarrollo próximo es una manera de referirse tanto a las funciones que se están desarrollando ontogenéticamente para un particular periodo de edad (objetivo) y el estado de desarrollo del niño en relación con las funciones que idealmente debe realizar (subjetivo). En este respecto, la zona de desarrollo próximo es tanto un descubrimiento teórico como empírico. (p. 50)

La referencia a una dimensión objetiva de la zona refleja, de acuerdo a Chaklin, las relaciones estructurales históricamente y objetivamente construidas en el momento histórico que el niño vive; esto hace que la zona para un momento de edad, en una sociedad y cultura particular y en un momento histórico dado tenga ciertas propiedades normativas, en tanto refleja las demandas institucionalizadas y las expectativas en una particular tradición de práctica social. La referencia a la dimensión subjetiva apunta hacia el estado subjetivo desde el que se interpretan y asumen esas demandas.

Esta particularidad de la zona, como algo que no es un atributo del sujeto y que rebasa sus funciones cognitivas, es también enfatizada por del Río y Álvarez (2007), quienes argumentan que este concepto cobra mayor sentido si se le ve desde una perspectiva funcional y ecológica; esta perspectiva busca superar las dicotomías entre lo externo y lo interno, lo material y lo mental, el organismo y su medio de actividad; estos autores hacen énfasis en que, en la evaluación e intervención, se necesita considerar todos los procesos, tanto los internos como los externos; reconociendo sujeto y medio como unidad dinámica, argumentan por una visión ecológica de la mente, que concibe los procesos psíquicos como distribuidos en el entorno en que se vive y actúa; la zona de desarrollo próximo es un ambiente vivo, en cambio constante; la actividad en la zona es entendida como actividad que busca la creación de nuevas vías y estrategias para percibir y actuar en el ambiente vital; estas nuevas vías implican tanto "el tejido extracortical de la cultura como nuevas formaciones neurológicas" (p. 303). Estos autores expresan, con convincentes argumentos, que el concepto de zona de desarrollo próximo debe elaborarse para capturar la complejidad 
del marco históricocultural; además de una herramienta valiosa para el diseño educativo que busca el desarrollo de funciones mentales superiores en sujetos particulares, la zona de desarrollo próximo puede ser una herramienta para construir "una epistemología de la mente humana en permanente evolución" (p. 303).

Las consideraciones teóricas que hemos presentado hasta aquí propician una mirada de mayor complejidad a la evaluación educativa de la que ha sido característica de esa práctica; desde el enfoque históricocultural, el desarrollo y el aprendizaje humanos guardan una compleja y dinámica relación entre sí que los hace inseparables de las actividades que implican, las herramientas y símbolos mediante los cuales dicha actividades se realizan, los diversos contextos donde las actividades se realizan y las relaciones socioculturales que los atraviesan.

Por desgracia, esta complejidad tiende a perderse de vista cuando la evaluación del aprendizaje y del desarrollo se realiza sin tomar en consideración estas complejas dinámicas. Se simplifican sobremanera los procesos cuando la evaluación se hace sobre premisas incuestionadas, como el entendido de que el sistema educativo público representa iguales oportunidades para todos por ser obligatorio o que los exámenes que determinan el pase de una asignatura o el movimiento de un grado o nivel al siguiente son indicadores completamente objetivos del aprovechamiento académico del sujeto, el cual, dicho sea de paso, se evalúa al margen de la efectividad de las prácticas de enseñanza (Álvarez Méndez, 2001). Al hablar de la evaluación por examen, en cualquiera de sus modalidades, pocas veces se reflexiona sobre los supuestos en que dicha práctica se sostiene y las consecuencias que tienen como dispositivos de estigmatización, exclusión y marginación sobre sectores poblaciones (Álvarez Méndez, 2005). Estas consecuencias son particularmente duras en los sectores más desfavorecidos de la sociedad, por ejemplo, personas que viven en condiciones de pobreza (Baquero, 2001; Portes, 2005; Portes \& Vandeboncouer, 2003), personas de trasfondos culturales y lingüísticos diferentes a los de la mayoría, y personas con condiciones físicas o psicológicas que requieren educación especial (Artiles, 2003; Mitjans Martínez, 2009; Gindis, 2003).

De la epistemología, la teoría y la metodología del enfoque históricocultural derivan unos principios para orientar la práctica de la evaluación psicoeducativa. Si bien esta práctica le da importancia a los aspectos técnicos, es decir, al cómo evaluamos (con qué estrategias y con qué instrumentos), esta importancia está en función de dos cuestiones que le preceden: por qué evaluamos y para qué lo hacemos.

Volumen 11, Número 1, Año 2011, ISSN 1409-4703 
Desde el marco conceptual del que partimos, la evaluación se hace, porque estimamos necesario conocer, es decir, elaborar el entendimiento más amplio y la compresión más profunda posible de la situación social de desarrollo (que siempre implicará aprendizaje) de la persona que está siendo evaluada. Este conocimiento se estima indispensable para la planificación, el diseño y la evaluación de estrategias de intervención para promover el aprendizaje y el desarrollo del sujeto en cuya formación participamos. En este propósito está implícito, aunque no siempre tengamos conciencia de ello, que al evaluar el aprendizaje de nuestros alumnos siempre estamos evaluando, además, nuestra propia enseñanza y las condiciones en que se realiza.

\section{CONSIDERACIONES PRÁCTICAS}

Podrá suponerse la complejidad que entraña la aplicación de un modelo conceptual como el que acabamos de sintetizar. A la tarea, de altísima dificultad en sí misma, se suman (no podría ser de otra manera) las condiciones históricoculturales específicas en que se originan las prácticas de evaluación psicoeducativa. Sobre este particular, Arias Beatón (2001) señala la falta de reflexividad histórica al pensar la evaluación y al pasar por alto que la misma es una producción humana que está sujeta a formas alternas de práctica.

Por su parte, Álvarez Méndez (2005) elabora sobre este punto cuando nos recuerda el origen históricocultural de la evaluación al apuntar que muchas de las prácticas vigentes en el campo de la evaluación educativa surgieron en las décadas sesenta y setenta del siglo pasado "en contextos ideológicos muy conservadores en los que primaba la preocupación por soluciones técnicas que garantizaban respuestas eficaces para la selección ante el aumento en la escolarización" (p. 18). El presente históricocultural, con la notable presencia de la globalización y la ideología neoliberal que la alimenta, ha impuesto otras demandas y prácticas en que se han fundido el llamado rendimiento de cuentas ("accountability"), unos particulares modelos de calidad educativa y unas tecnologías muy específicas para evaluar dicha calidad y regular la actividad pedagógica (Rodríguez Arocho, 2009).

Las referidas condiciones históricoculturales se concretan en prácticas institucionalizadas que regulan la actividad docente. Problemas en la formación docente pueden resultar en una limitada comprensión de la necesaria articulación entre filosofía educativa, prácticas de enseñanza y evaluación (Álvarez Méndez, 2001; Cruz González, 2009; Rodríguez Arocho, 2010). A esto se suman una formación deficiente en modelos y estrategias de evaluación, la práctica de no especificar claramente los objetivos de Volumen 11, Número 1, Año 2011, ISSN 1409-4703 
evaluación, y la escasez de adiestramiento en estrategias de evaluación no tradicionales (Cruz González, 2009). Estas observaciones se corresponden con las conclusiones a las que llega Serrano García (2009) tras una revisión de la literatura sobre el tema de evaluación del aprendizaje. En dicha revisión se observa que: 1) muchos profesores y profesoras no definen claramente sus criterios de evaluación, 2) la evaluación se practica disociada del proceso de enseñanza-aprendizaje, 3) las estrategias más frecuentes son los exámenes, los escritos individuales y las presentaciones orales individuales, y 4) el control del proceso de evaluación recae principalmente, si no únicamente, en el profesor o la profesora.

Hay que reconocer que estos hallazgos se sostienen sobre una particular cultura escolar y que los escenarios institucionales imponen barreras a otras formas de hacer evaluación, presentando en ocasiones contradicciones que pocas veces se debaten públicamente. Una de esas contradicciones es la exigencia programática en las instituciones escolares de adoptar modelos constructivistas (Rodríguez Arocho, 2006), para orientar la enseñanza y luego tener que realizar la evaluación del aprendizaje con modelos fundamentalmente conductistas. El discurso de un aprendizaje que debe diseñarse partiendo de la premisa de que el conocimiento es construido mediante actividades que tengan pertinencia para el estudiante y que sea significado en actividades colaborativas que promuevan un pensamiento flexible choca frontalmente con la exigencia de evaluar ese mismo aprendizaje mediante exámenes o pruebas objetivas que se contestan individualmente, donde el conocimiento se presenta, la mayor parte de las veces, descontextualizado y donde se espera una respuesta correcta fija que no admite discusión, mucho menos negociación de significados. Salir de esta encrucijada implica comenzar a practicar formas alternas de evaluación. Las prácticas más radicales sólo pueden realizarse en instituciones educativas que asuman modelos alternos de educación, como el caso de la escuela sin grados (Docentes de la Escuela 57, Baquero \& Greco, 2007). También, se han documentado formas muy diferentes de valoración del aprendizaje y el desarrollo en proyectos novedosos donde participan estudiantes fuera de horario escolar (Cole \& Distributed Literacy Consortium, 2006; Hedegaard \& Chaklin, 2005), aunque en éstos no hay la exigencia institucional de una nota o calificación.

No obstante, hay otras prácticas y principios que pueden irse incorporando a nuestras rutinas educativas y que viabilizan promover cambios; así lo demuestran el trabajo de Lidz \& Gindis (2003), sobre las tendencias actuales en la evaluación dinámica, el trabajo Arias Beatón (2001), sobre teoría y práctica de la evaluación y diagnóstico en la educación y el 
desarrollo, los trabajos de Kozulin \& Gindis (2007) y Gindis (2003), sobre educación remediativa para potenciar el desarrollo en niños y niñas con diversas necesidades especiales. Igualmente, derivan implicaciones prácticas del trabajo del colega español Juan Manuel Álvarez Méndez (2001, 2003, 2005), cuya lectura recomendamos a practicantes de la educación en todos sus niveles que tengan interés en una reflexión seria sobre la evaluación educativa, sus propósitos, sus prácticas y las consecuencias de éstas.

En trabajo reciente, Serrano García (2009) examina las bases conceptuales y los retos que implica la evaluación educativa y sintetiza pautas para su práctica que armonizan bien con los trabajos acabados de mencionar y que elaboraremos en esta sección, así como el marco conceptual trabajado en la sección anterior. Esta autora plantea que debe darse énfasis a "la evaluación formativa y colaborativa, cuyos propósitos incluyen medir y fomentar el aprendizaje por medio de interacción, conversación e intercambio, análisis crítico y reflexión, cooperación y participación". Para esta evaluación, ella propone estrategias como la redacción de narrativas reflexivas y los proyectos e informes en equipo.

A estas estrategias, Álvarez Méndez (2003) agrega la entrevista, la elaboración y debate de trabajos, exposiciones, diálogos, negociaciones, discusión entre grupos y análisis crítico de lecturas. Ambos autores coinciden en subrayar que el estudiante debe ser partícipe de su propia evaluación. Esta participación puede lograrse mediante la autoevaluación y la evaluación por pares, la determinación conjunta entre docente y estudiantes de los criterios y pesos de la evaluación y adjudicación dialogada de las calificaciones finales. La evaluación final debe estar precedida por retroalimentación continua y a tiempo, es decir, con tiempo suficiente para responder a ella.

Asumir la evaluación formativa como principio fundamental de práctica quiere decir que lo primero que hay que hacer es precisar cuál es el propósito que perseguimos con la evaluación. Álvarez Méndez (2005), quien suscribe este principio, plantea la búsqueda y construcción de conocimiento como la razón de ser de la evaluación:

Necesitamos concebir y practicar la evaluación como otra forma de aprender, de acceder al conocimiento, y una oportunidad más de aprender y continuar aprendiendo. Necesitamos convertirla en un medio por el cual los sujetos que aprenden expresan su saber que no es sobre lo inmediato, sino saber acumulado integrado habitualmente en los modos de razonar y de actuar en un estado (de formación) que es dinámico, inestable, abierto, inseguro, inmaduro, provisional, lleno de dudas y contradicciones, de sobresaltos. (pp. 75-76) 
Hay varias indicaciones para la práctica en esta concepción de la evaluación. Lo primero es resistir el formato o forma de examen que nos devuelve de forma mecánica y repetitiva lo enseñado en clase, porque lo que evalúa no es aprendizaje, sino capacidad para codificar, archivar y recuperar información sin que medie un proceso reflexivo y crítico (Alvarez Méndez, 2003, 2005). El examen, en su forma más tradicional, sólo ofrecerá indicadores fijos de un saber ya acabado que no admite refutación y debate. La respuesta incorrecta se hace equivalente a la ignorancia y se castiga; no hay indagación sobre el origen y la estructura del error.

En esta modalidad nos enfocamos en el producto y desconocemos el proceso de construcción de conocimiento. Vemos la ejecución fosilizada en una nota o calificación y no la dinámica que subyace a la ejecución. Producimos mucha información descriptiva, pero ninguna explicación de las dinámicas del aprendizaje y el desarrollo del alumno. En otras palabras, hacemos lo inverso de lo que nos demanda el método genético, con lo cual quedamos en los análisis reduccionistas y simplistas de estos procesos. Ante esta situación, Álvarez Méndez (2005) nos conmina a tomar posición y nos advierte que debemos ser conscientes de que hay formas diversas de asumir la evaluación del trabajo escolar. Podemos asumirla como la práctica de "confirmar ignorancias, descalificar olvidos, penalizar aprendizajes no adquiridos" o podemos asumirla como la práctica "constructiva y solidaria" que explora e indaga la naturaleza y el carácter de la respuesta, que "explica y comunica razonadamente mediante información comprensible y argumentada" el resultado del proceso, en este caso la corrección.

Cuando evaluamos un trabajo o un examen con el fin de apreciar la calidad de la respuesta y el saber en la materia de quien lo realiza, lo que debemos buscar es conocer el proceso de elaboración que el alumno ha seguido, comprender la utilización de estrategias de resolución que pone en juego, la capacidad de argumentación, que muestra, las causa y motivos que provocan los errores. Debemos considerar de igual modo los aciertos, para discriminar entre respuestas elaboradas y aquéllas que obedecen a aciertos casuales. (pp. 77-78)

Un examen o trabajo, cuyo resultado no se analiza y no se discute con el alumno, servirá para la adjudicación de una calificación, pero pierde su valor de uso como herramienta de aprendizaje y desarrollo. En la práctica, la corrección informada y dialogada del trabajo es una herramienta tanto de enseñanza como de aprendizaje. La discusión del examen o trabajo debe indicar, en el momento oportuno (no cuando ya sea tarde para 
mejorar), no sólo en qué consistió el error, sino por qué se cometió y cómo puede superarse en una ocasión futura. La formulación de preguntas y el pedido de aclaración y elaboración pueden ser útiles para develar la dinámica interna del error. Nos permitirá entender cómo se aborda la tarea y nos ayudará a ver procesos cognitivos en acción y a inferir estilos de aprendizaje; en otras palabras, nos permite pasar de la descripción a la explicación. Desde esta explicación se facilita intervenir en el proceso de aprendizaje; desde una perspectiva en que el aprendizaje debe promover el desarrollo el error no se conceptúa como algo definitivo, sino como algo transitorio (Álvarez Méndez, 2003). Debe entenderse como un momento en el proceso dinámico que es el aprendizaje.

La adjudicación de notas también debe reconocer los principios de diversidad en formas de aprendizaje y desarrollo que hemos elaborado en la sección anterior; esto quiere decir que debe haber diferentes formas o estrategias, pero siempre con los objetivos y los criterios de evaluación claramente establecidos y comunicados al estudiante con anterioridad a la tarea. Hacer explícitos y discutir los criterios por los cuales los trabajos serán corregidos, valorados y calificados es una condición necesaria en la evaluación orientada al aprendizaje (Álvarez Méndez, 2005). En el proceso, se modela y construye colaborativamente el entendido de qué es lo que se considera importante en el aprendizaje.

La resistencia al examen tradicional de respuesta fija debe acompañarse en la práctica con evaluaciones formativas variadas y múltiples que permitan establecer regularidades y patrones que representen un mejor perfil del estudiante, al tiempo que reconocen la variedad en estilos de aprendizaje. Evaluar el aprendizaje con uno o dos exámenes del mismo tipo en un semestre no permite una comprensión amplia de los procesos de desarrollo y aprendizaje del alumno. Las preguntas cerradas directamente referidas a los contenidos explicados o trabajados en clase no nos permiten "comprobar si los alumnos son capaces de defender las ideas en las que creen y de argumentar para criticar aquéllas que consideran que no son aceptables, evitando caer en la simple descalificación cuando enfrentan sus ideas con las ideas de otros" (Álvarez Méndez, 2005, p. 96). En consecuencia, deben promoverse aquellas formas de evaluación que necesitan expresión y elaboración de ideas propias con respecto a lo estudiado. Esta elaboración puede orientarse mediante preguntas guías, en cuya formulación y redacción pueden y deben participar los alumnos y las alumnas. Esta elaboración es una herramienta que permite explorar la significación del material estudiado/evaluado en el contexto de vida. 
Como ejemplo de lo expuesto, presento una tarea asignada en el curso de Aprendizaje Humano que dicto a nivel de pregrado. Para introducir el tema de la situacionalidad históricocultural del desarrollo humano, pedimos a cada estudiante que vaya a la hemeroteca, busque y analice un ejemplar de la prensa del día de su nacimiento. Debe elaborar un ensayo breve con sus impresiones sobre lo que leyó y reflexionar sobre la pregunta de si la situación general del contexto es igual o distinta de la que se vive en el momento presente. Deben ser específicos en cuanto a diferencias y similitudes. La discusión colectiva de estos trabajos siempre resulta en el planteamiento de temas complejos, como que el desarrollo implica tanto estabilidad como transformación, que crecimiento y desarrollo no son la misma cosa, que el imaginario social se construye a partir de las herramientas de que se dispone, que hay dinámicas y producciones sociales y culturales que propician formas distintas de desarrollo; estos puntos no son de entrada planteados por la profesora, sino que llegamos a ellos analizando e interpretando las lecturas que cada quien hizo. Estas lecturas se han enriquecido cuando hemos tenido grupos con alguna dispersión en edad, etnia y nacionalidad.

Se observan, de inmediato, diferencias en trasfondo e intereses, en experiencias de vida y expresiones de desarrollo. Algunos estudiantes se enfocan en las formas de la publicidad, las características y los precios de los objetos y servicios y lo que implican en cuanto a su accesibilidad, mientras otros se enfocan en la incidencia de problemas y situaciones sociales y hacen comparaciones con lo que han escuchado de sus padres y abuelos. Se revelan lagunas en conocimiento, particularmente con respecto a asuntos internacionales. Particularmente ejemplar fue la situación de una estudiante que se mostró sorprendida de que en el año de su nacimiento ya existía el conflicto palestino-israelí; esto ha sucedido en más de una ocasión. También, se revelan agudezas, como el estudiante que notó en las esquelas más muertes de personas jóvenes y lo vinculó a la criminalidad y la epidemia del SIDA. Como es evidente, este es un trabajo en donde cada producción será diferente; lo que importa en el ejercicio es exponer la riqueza de las narrativas personales. El análisis y las discusiones que se generan en el aula, a partir de éstas, aseguran que el aprendizaje se significará desde una vivencia que permite examinar la propia situación de desarrollo; además, se crea un espacio valioso para la expresión escrita y oral, al tiempo que se promueve la indagación colaborativa.

Como hemos establecido, el marco conceptual del que partimos concede un rol central al lenguaje (tanto oral como escrito), al manejo crítico de conceptos científicos y a la Volumen 11, Número 1, Año 2011, ISSN 1409-4703 
reflexión; por ello, promueve el uso del ensayo reflexivo sobre el tema bajo estudio, que debe ser evaluado con las indicaciones arriba mencionadas. La elaboración de narrativas, por parte de los alumnos, ofrece una ventana de oportunidad para aproximarnos no sólo al manejo de contenidos, sino a procesos de percepción y atención, abstracción y generalización, deducción e inferencia, razonamiento y, en el caso de la escritura creativa, imaginación y creatividad.

Asimismo, se ofrece esta oportunidad en las pruebas orales. La inclusión de preguntas guía que exijan la toma y defensa de una posición puede servir, además de para observar las competencias ya mencionadas, para aproximarnos al sentido subjetivo del estudiante o la estudiante, sus juicios de valor y la forma en que significa el aprendizaje. Por supuesto, la corrección del ensayo reflexivo, de la escritura creativa y de la prueba oral deberán realizase en las condiciones ya mencionadas: especificar claramente los objetivos de la tarea y los criterios de evaluación, así como explicar y justificar la evaluación. Este intercambio escrito u oral sobre el trabajo se considera de gran valor para promover el desarrollo de las competencias antes mencionadas.

Para ilustrar la aplicación de lo expuesto cito otro ejemplo: el uso que doy al ensayo reflexivo en el curso de postgrado Acercamientos Psicológicos al Estudio de los Procesos Cognitivos; como parte de los requisitos del curso deben preparase cinco ensayos reflexivos, orientados por unas preguntas guías; en el curso se estudia la cognición desde el modelo de procesamiento de información (en sus vertientes representacional y conexionista), la epistemología genética, el enfoque históricocultural, la neuropsicología (en la vertiente tradicional y en la luriana) y la neurofenomenología. Cada ensayo debe orientarse a discutir cómo define el modelo estudiado la cognición, cómo la explica y qué juicio crítico le merece la explicación. Según avanza el curso, los ensayos deben elaborar sobre las variaciones entre los modelos con respecto a estas tres cuestiones. La guía para la elaboración del ensayo, que se reparte y discute en clase, incluye: una definición breve de lo que es un ensayo reflexivo, las lecturas mínimas que deben utilizarse y el formato (que incluye una breve introducción, la elaboración del tema, la valoración crítica y las referencias utilizadas). La guía también incluye los criterios de evaluación y valores de ponderación de los mismos. Estos son: 1) puntualidad en la entrega (la fecha de entrega está indicada en el calendario de trabajo del curso: 10 puntos, 2) introducción: 10 puntos, 3) dominio del material estudiado, entendido como manejo adecuado de los conceptos fundamentales, entendimiento de las proposiciones de la teoría, identificación de problemas teóricos y metodológicos en la 
aproximación y capacidad de vincular la literatura revisada con material estudiado en otros cursos tomados, en lecturas independientes y en experiencias personales: 40 puntos y 4) propiedad en la redacción, definida como formato, dominio de reglas gramaticales, de ortografía, manejo adecuado de citas y uso de referencias: 10 puntos. Cada trabajo es evaluado en forma narrativa en una hoja diseñada para ese propósito que incluye el nombre del estudiante, el título del trabajo, la puntuación otorgada en cada criterio y un comentario en el que se ofrece una explicación de la valoración, se destacan las fortalezas y señalan las limitaciones del trabajo; en este caso, se hacen recomendaciones específicas para atender los señalamientos. Hay discusión oral de las evaluaciones cuando el estudiante lo solicita.

Los ensayos narrativos, como en el ejemplo anterior, y los exámenes (recuérdese que la opción es por exámenes de discusión) se suelen realizar, generalmente, de manera individual. No obstante, como es de suponer, el modelo del que partimos supone que la cognición está distribuida y privilegia el trabajo en grupos o equipos. Los proyectos, los informes grupales, las discusiones y los debates son algunas de las actividades representativas del trabajo colectivo útiles a la forma de construcción de conocimiento que Wells (1999) llama "indagación dialógica". Esta indagación se refiere al análisis conjunto que una comunidad de aprendices realiza de un determinado contenido bajo la guía de un docente que facilitará, mediante preguntas y comentarios, el ejercicio de la reflexión crítica que permite la vinculación de lo estudiado a los contextos de actividad.

Hemos utilizado la modalidad de proyectos e informes grupales en los cursos de Aprendizaje Humano, de Problemas en la Enseñanza de la Psicología y el Preseminario de Psicología General, todos cursos de postgrado. El tamaño de los grupos se determina en función de la cantidad de estudiantes en el aula y de los intereses de éstos. En cursos de postgrado, el trabajo tiende a ser en parejas o en grupos de tres o cuatro personas. Igual que en el ejemplo del ensayo narrativo, para el trabajo grupal también se distribuye una guía donde se define y se delimita la tarea y se establecen plazos límites. Se deja a la discusión y decisión de los participantes el formato que van a seguir para su presentación y se estimula la creatividad. Igual que en el caso anterior, se circula una hoja con los criterios y pesos de evaluación.

Esta información se utiliza para diseñar la hoja de evaluación que los pares y la profesora completarán luego de la presentación. Los criterios que se utilizan son: presentación y logro de los objetivos, organización de la actividad, pertinencia de la información presentada, dominio del material, uso de recursos tecnológicos y/o humanos e 
interacción eficaz con el grupo. La valoración se hace en una escala numérica de 1 a 3, y hay que explicarla y comentar fortalezas y debilidades. Aparte, el equipo de presentadores evalúa tanto su presentación como el trabajo en el equipo en términos de distribución de tareas, cumplimiento de acuerdos y compromisos en las fechas establecidas, surgimiento y resolución de conflictos o desacuerdos, satisfacción personal con el trabajo en el grupo. En ambos casos las evaluaciones se discuten con los evaluados. Se han presentado situaciones en que, en la preparación del trabajo, hay quejas de algunos miembros con respecto a otros. La primera opción es que el grupo trate de plantear y resolver sus dificultades. Sólo cuando esto no resulta interviene la profesora, involucrando a todas las partes. En los casos presentados las evaluaciones estudiantiles no son mera forma. Reciben un peso en la evaluación global.

En la modalidad de trabajo grupal se observa la participación del estudiante en su propio proceso de evaluación. Álvarez Méndez (2005) y Serrano García (2009) argumentan sobre la importancia de que los estudiantes y las estudiantes participen en todas las etapas del proceso de evaluación de su aprendizaje, desde pensar y diseñar los criterios, hasta operacionalizarlos y aplicarlos. Como hemos visto, en las modalidades de trabajo deben estar presentes la autoevaluación y la evaluación por pares y darles un peso real en la valoración de la ejecución académica. Decimos "real", porque a veces estas actividades se incluyen en las rutinas del aula, pero no se les da peso en la valoración final del trabajo, porque no se le reconoce al estudiantado ni la capacidad ni las destrezas para evaluar. Desde la perspectiva históricocultural, está claro que se trata de capacidades y destrezas que pueden aprenderse y desarrollarse con la debida mentoría. Como señala Broadfood (1997, citado en Álvarez Méndez, 2003):

Cuando los alumnos llegan a implicarse en el proceso de poner la nota en el examen y se les anima a reflejar sus necesidades de rendimiento y desarrollo, se les están enseñando las habilidades de autoevaluación, autopresentación y autogestión, que están siendo reconocidas crecientemente como habilidades fundamentales, no sólo para las escuelas sino en el mundo del trabajo también. (p. 100)

Nuestra experiencia y la de otras colegas en el desarrollo de comunidades de aprendizaje confirma que la interacción, el diálogo y la práctica guiada desde una mentoría consciente y responsable (Serrano García, 2006) promueven el desarrollo de actitudes y comportamientos que van mucho más allá de la mera adquisición y reproducción de información (Fariñas León, 2005; Rodríguez Arocho \& Alom Alemán, 2009). 
En nuestra experiencia, estos comportamientos promueven múltiples instancias donde estudiantes con mayor nivel desarrollo colaboran espontáneamente con su pares para ayudarles en una tarea y que éstos, luego reciprocan cuando son ellos lo que están en posición de hacerlo. La solidaridad, la corresponsabilidad, el compromiso y el sentido de grupo se construyen en actividades concretas en las que se aplican conocimientos a la solución de problemas en la realidad social que se vive.

En una publicación reciente hemos descrito en detalle un proyecto que se extendió por diez años y en el que participamos docentes universitarios de varias disciplinas y estudiantes de nivel secundario, en sus dos años previos al ingreso a la universidad (Rodríguez Arocho \& Alom Alemán, 2009). El proyecto se orientó a la construcción de comunidades de aprendizaje concebidas para construir colaborativamente intereses, conocimientos y destrezas en investigación desde una perspectiva interdisciplinaria, de diálogo entre las ciencias sociales y las ciencias naturales. Con fundamento en el marco conceptual del que partimos, las actividades se orientaron a examinar la ciencia como una práctica social, situada históricamente y mediada culturalmente, por lo que, además de métodos y estrategias de investigación (cuantitativa y cualitativa), se buscó fomentar la comprensión de sus fundamentos filosóficos y de su dimensión ética. El momento del desarrollo de los participantes y el tiempo que pasaron en el proyecto nos ofreció una perspectiva de tiempo que nos permitió apreciar transformaciones en las formas de aprender.

Desde 1989 hemos tenido experiencia en comunidades de aprendizaje y de práctica de docentes/investigadores, estudiantes de pregrado y estudiantes de postgrado donde hemos observado procesos de desarrollo y aprendizaje similares. Por supuesto, las actividades a realizar en estas comunidades variarán en función de las características de los participantes y del entorno del que forman parte.

Tanto en las consideraciones teóricas como en las prácticas, hemos hecho énfasis en la perspectiva evolutiva. En el enfoque históricocultural el aprendizaje y el desarrollo son procesos caracterizados por cambios que se insertan en una historia de transformaciones cualitativas. Por lo tanto, es importante la mirada a estos cambios. La valoración de nuestra propia efectividad está condicionada a que podamos precisar un antes y un después Las evaluaciones, por ende, deben mirarse desde una perspectiva evolutiva de modo que se inscriban en el historial de desarrollo del sujeto (Vygotski, 1931b). Sólo ese historial, sólo el valor de una evaluación en un conjunto puede ofrecer información que permita establecer “conexiones, nexos y movimientos" en el aprendizaje. Podemos aumentar el valor de 
herramientas de evaluación cualitativa como el registro anecdótico que a veces llevamos cuando trascendemos el registro de descriptores aislados del sujeto y de su ambiente y buscamos establecer relaciones y vínculos entre ambos. El registro de incidentes en un orden cronológico no es un historial de desarrollo, es meramente una crónica descriptiva. El historial debe intentar la explicación de las dinámicas internas y ver el desarrollo como un todo único, coherente y dinámico. No obstante, la evaluación educativa tradicional se parcela en materias y exámenes independientes e inconexos a ese desarrollo. El trabajo de evaluación en equipos docentes que comparten alumnos es una alternativa para dar sentido al conjunto de ejecuciones del estudiante o la estudiante.

Como puede inferirse de las prácticas de evaluación presentadas, la práctica que se sostiene en el enfoque históricocultural está mucho más interesada en la significación del diagnóstico clínico del aprendizaje que en la significación estadística (Arias Beatón, 2001). Se busca trascender el análisis aritmético, mecánico, que se ampara en la psicometría tradicional. En cambio, se busca una interpretación creativa, que otorgue significado a la cantidad y diversidad de información recopilada y la coloque en el contexto del que surge (Vygotski, 1931). La reflexión de Vygotski sobre este tema debe movernos a la reflexión:

Las mediciones aisladas siguiendo un patrón, sin la idea o la intuición sobre la estructura general, es poco probable que pueda movernos de lugar... La tarea de la metodología consiste no sólo en enseñar a medir, pero también en enseñar a ver, a pensar, y esto significa que el miedo excesivo a los llamados momentos subjetivos en la interpretación y el intento de obtener los resultados de nuestras investigaciones mediante una vía puramente mecánica y aritmética, como tiene lugar en el sistema Binet, son erróneos. Sin el perfeccionamiento subjetivo, es decir, sin el pensamiento, sin la interpretación, sin el desciframiento de los datos y el análisis de los datos no hay investigación científica. (p. 122)

Concebida como un proceso de búsqueda de conocimiento, la evaluación educativa de carácter formativo implica investigación, por lo que se justifica la generalización del pensamiento expresado en esta cita al campo de la actividad evaluativa. La confiabilidad y la validez estadísticas dicen poco si no consideramos la fiabilidad y la validez ecológica, si no interpretamos el dato desde un marco general donde se contextualice y signifique. Esta es un área particularmente sensitiva cuando se trata de la valoración del aprendizaje y del desarrollo de personas con necesidades educativas especiales. Los índices absolutos de 
limitaciones perceptivas, motoras, cognitivas y afectivas dicen poco si no se significan en la particular situación de desarrollo de la persona afectada.

En estas situaciones no es la presencia o ausencia de una condición o el grado de su intensidad de la misma, según determinado por instrumentos de medición, sino la forma como la familia, la comunidad, la sociedad y la cultura conceptúen y traten dicha condición. Las implicaciones para la evaluación psicoeducativa de la referida población cambian radicalmente si se parte de la premisa de que "el niño cuyo desarrollo está complicado por el defecto no es simplemente un niño menos desarrollado que sus coetáneos normales, sino desarrollado de otro modo" (Vygotski, 1931, p. 12). Este desarrollo alternativo puede ser promovido por una enseñanza que reconozca que la vivencia psicológica de la condición limitante no surge originalmente de la limitación, sino secundariamente, "sino de las consecuencias sociales que son provocadas por el defecto" (Vygotski, 1931, p. 12). El análisis de la sobrerrepresentación de niños y niñas de grupos de razas y etnias minoritarias en las estadísticas de deficiencias, retraso o rezago cognitivo se ha apoyado recientemente en este mismo argumento (Artiles, 2003).

Vygotski hizo las expresiones sobre el carácter secundario de las deficiencias en el desarrollo en su texto sobre defectología. Este término, que en el momento en que Vygotski escribió significaba estudio del defecto, abarcaba un campo amplio donde se fundían la psicología escolar y la educación especial (Gindis, 2003). A la defectología correspondían la evaluación, el diagnóstico y la educación de personas con necesidades especiales. Vygotski hace una contribución importante al campo al plantear que muchas limitaciones que consideramos orgánicas están subordinadas a los arreglos sociales.

Por su lógica, este razonamiento es generalizable a otras condiciones de privación sociocultural. La pobreza, la exclusión y la marginación social no son condiciones naturales, sino productos de la acción y la inacción humanas con consecuencias negativas para amplios sectores de la población (Portes, 2005; Portes \& Vandeboncouer, 2003). La lógica que emana del enfoque históricocultural nos conmina a desnaturalizar los fenómenos, aún aquéllos que por su apariencia encajan perfectamente en el calificativo de fenómeno natural. Tomemos, por ejemplo, el reciente terremoto en Haití.

A los dos días del terremoto en Haití, David Brooks (2010), uno de sus columnistas regulares del diario New York Times, llamó la atención sobre la historia incompleta de los números cuando se trata de valorar el significado de un evento. Comienza comparando los datos del terremoto en Haití con los del último terremoto grande en el estado de California. 
Según los datos, el 12 de enero de 2010 un terremoto de magnitud 7.0 sacudió a Haití, con el saldo estimado de más de 200,000 personas muertas, según los medios de comunicación masiva. El 17 de octubre de 1989 un terremoto de la misma magnitud sacudió el área de la Bahía en la parte noreste de California causando la muerte a 63 personas. A estos datos podemos agregar ahora el reciente terremoto en Chile. Las últimas cifras disponibles al momento de redactar este trabajo estiman en cerca de 500 el número de muertos por terremoto ocurrido allí el 28 de febrero de 2010.

Las comparaciones entre dos registros iguales en magnitud y un registro aún mayor nos permiten establecer una diferencia con respecto al lugar en una escala numérica. Sólo eso. La explicación a la gran deferencia en cuanto a las pérdidas en vidas humanas e infraestructura hay que buscarla no en las fuerzas de naturaleza (evidentes, sin duda), sino en las condiciones de vida (las construcciones, los medios y la capacidad de respuesta en los servicios de ayuda, etc.). El valor del número, en este caso, está sujeto a interpretación, como está sujeta a interpretación la nota en un examen. Desde dónde y con qué propósito se elabora la explicación, es el último punto que consideraremos en este examen de consideraciones prácticas en la evaluación educativa.

El tema del énfasis en significación estadística frente a una significación más de carácter hermenéutico-reflexivo, toca otros asuntos que parecen haber sido naturalizados, como el llamado fracaso escolar, el abandono de la escuela y la diversidad (Álvarez Méndez, 2003; Baquero, 2001). En los índices de fracaso se subrayan, una y otra vez los resultados de evaluación que se interpretan como deficiencias de los alumnos o de padres que no se ocupan, construyendo una sospecha permanente sobre sus capacidades para tener éxito en la escuela. Separamos, de este modo, al sujeto de su particular situación de desarrollo y las barreras y límites que se establecen en múltiples instancias a la posibilidad de su educación y desarrollo.

La última pregunta y, a nuestro juicio, tan importante como la primera, que nos refería a las razones para realizar la evaluación, se refiere al propósito de la evaluación. Desde el enfoque históricocultural, la respuesta a esta pregunta siempre será la misma: para orientar el aprendizaje y, en consecuencia, el desarrollo. La evaluación aquí no termina con el diagnóstico clínico, con el análisis del resultado en la tarea; ésta es sólo un medio para planificar la siguiente intervención. Este es el sentido de la evaluación formativa. Álvarez Méndez (2003, p. 116) sintetiza muy bien el sentido de esta actividad cuando dice: 
Más allá de las definiciones, por formativa debe entenderse aquella evaluación puesta al servicio de quien aprende, aquella que puede ayudar a crecer y desarrollarse intelectual, afectiva, moral y socialmente al sujeto. En la práctica se traduce, en el caso de la corrección de un ejercicio o de un examen, en una actividad interactiva por medio de la cual el profesor aporta al alumno las informaciones relevantes complementarias por medio de las cuales puede ampliar información o precisar conocimientos y también por medio de las cuales advierte de la necesidad de corregir su representación del problema o aclarar cuestiones confusas. En este caso, la misma información que aporta la corrección, se convierte ella misma en fuente primaria y texto de aprendizaje.

En el caso de la evaluación del trabajo en el aula, hemos hecho énfasis en el valor constructivo del análisis del error para aportar a alumnos esas informaciones relevantes que le permitirán enfrentarlo y superarlo. En el caso de la evaluación psicoeducativa, hemos insistido en la necesidad de enfocarse en los procesos más que en los productos de la actividad neurocognitiva y de vincularlos con el historial de desarrollo del estudiante y con múltiples y variados indicadores de actividad.

Esta información se complementaba con información de la familia y de la escuela (Álvarez Arboleda, Moreno Torres \& Rodríguez Arocho, 2003; Rodríguez Arocho, 2007b). Como parte del protocolo de investigación que utilizamos en el Estudio del Desarrollo de Funciones Ejecutivas y Lenguaje en niños y niñas con y sin diagnóstico clínico de Trastorno de Déficit de Atención con Hiperactividad, se entregaba un informe de la evaluación realizada a la persona encargada del niño, con quien se discutía el contenido. Dicho informe, además de comenzar destacando las fortalezas del niño en las múltiples áreas evaluadas, incluía recomendaciones específicas para padres y maestros de suerte que pudieran atenderse conjuntamente las limitaciones encontradas. Con este proceder se buscaba superar limitaciones frecuentes en los informes psicoeducativos donde se presentan resultados, algunas veces formulados en términos técnicos que dificultan su compresión y uso por parte de cualquiera que no sea un especialista (Álvarez Arboleda, Cardona Vázquez, Moreno Torres \& Rodríguez Arocho, 2005) Se buscaba, además, que la evaluación cumpliera una función formativa y que pudiera servir para intervenciones que promovieran aprendizaje y desarrollo en el niño.

De las consideraciones prácticas que hemos presentado emanan varios principios rectores: el primero, es que nos plantea ver la evaluación como herramienta para promover 
el aprendizaje y el desarrollo; los otros principios han sido muy bien expresados por Álvarez Méndez (2005, p. 89), por lo que los tomamos de él:

transparencia (en los principios, en las intenciones, en las negociaciones, en los fines y en los usos); credibilidad (no basta con enunciar los principios, deben ser comprensibles para que sean creíbles como enunciados que orientan la práctica); coherencia epistemológica y cohesión práctica (acuerdo entre la concepción y las prácticas); aceptabilidad (está en la legitimación social y educativa); pertinencia (para justificar las decisiones que se adopten); practicabilidad (deben ser aplicables a las prácticas concretas de evaluación) y legitimidad (en cuanto acción social que debe ser moralmente correcta).

Por su particular congruencia con el marco conceptual del que partimos y de la pedagogía crítica por la que abogamos (Rodríguez Arocho, 2000b, 2009, 2010), terminamos este apartado reafirmando el último principio expresado: el principio de legitimidad. Aquí la legitimidad no remite a lo legal, a lo jurídico, sino a la dimensión ética. Toda práctica social conlleva un posicionamiento ético, aunque pocas veces reflexionemos sobre ellos. Nuestras creencias y nuestros valores están tan comprometidos como nuestras cogniciones y nuestros afectos en los actos que realizamos. Usamos nuevamente las palabras de Álvarez Méndez (2005), porque me parece que capturan muy bien el inevitable dilema ético que enfrentamos al pensar y hacer evaluaciones en educación y en psicología:

Bien claro se nos dice qué evaluar, cuándo evaluar y cómo evaluar, preguntas que indagan sobre cuestiones comunes de alcance burocrático y administrativo. Menos claras y normalmente ausentes en los discursos sobre evaluación son las preguntas que indagan al servicio de quién está la evaluación que practicamos, qué usos se hace de ella y, sobretodo, del los resultados que traducen los procesos y qué funciones (implícitas, no solo las proclamadas) desempeña. (p.52)

Independientemente del nivel de conciencia que tengamos de ello, cada una de las preguntas formuladas se contesta desde una particular ubicación filosófica, porque es una imposibilidad existencial pensar y hablar desde ninguna parte. Aunque el qué, el cómo y el cuándo evaluar tengan, en apariencia, un carácter más técnico que las preguntas a quien responde la evaluación, para qué y por qué se hace son preguntas interrelacionadas a las que procede aproximarnos como unidad de análisis cuando pensamos en la actividad evaluativa. 
Una práctica reflexiva, es decir, con conciencia, de la evaluación educativa tiene que confrontar un conjunto de dilemas interconectados y posicionarse ante ellos. Tiene que plantease y decidir si el interés es en evaluar la reproducción memorística de la información o su comprensión; si el interés es en medir el cumplimiento de los objetivos del programa curricular o entender las dinámicas que median el aprendizaje de los sujetos particulares que son evaluados y utilizar ese entendimiento para promover el desarrollo. Más importante aún, tiene que plantearse si la educación, como la actividad principal en nuestra humanización, continuará suscribiendo paradigmas simplistas o si moverá hacia paradigmas complejos. Las lógicas y las consecuencias previsibles de ambos acercamientos han sido analizadas por Morin (1999) y por Morin, Ciurana \& Motta (2002) en textos recientes que debería ser objeto de estudio y discusión en los programas de formación docente.

\section{Conclusión}

El enfoque históricocultural propone como tesis central que las actividades que realizamos los humanos, así como las cogniciones y los afectos que las acompañan, tienen un origen y organización que están condicionadas por una interacción compleja entre nuestra biología y nuestra historia cultural, las cuales se determinan recíprocamente.

El aprendizaje juega un rol fundamental en las expresiones que tome nuestra particular forma de lo humano, nuestra subjetividad. Dependiente de intercambios sociales, históricamente situados y culturalmente mediados, el aprendizaje promueve formas desarrollo. Actividades de aprendizaje mecánicas y rutinarias promoverán formas de pensar y hacer igualmente mecánicas y rutinarias. Actividades de aprendizaje que promuevan la reflexión crítica, la imaginación y la creatividad propiciarán formas de pensar y actuar reflexivas, críticas, imaginativas y creativas.

Concebida desde una epistemología positivista de la que deviene una racionalidad técnica, la evaluación será el resultado de la aplicación de estrategias y técnicas de medición para determinar eficaz e inconclusamente la efectividad del alumno para realizar tareas de manera independiente que permitan determinar su capacidad individual, establecer comparaciones con otros y afirmar su competitividad. Concebida desde una epistemología de la complejidad de la que deviene una racionalidad hermenéutica y reflexiva, la evaluación será el proceso por medio del cual se valorará colaborativa y dialogadamente el estado actual de la construcción de conocimientos de suerte tal que puedan diseñarse estrategias para la cooperación, la interacción con otros y la solidaridad.

Volumen 11, Número 1, Año 2011, ISSN 1409-4703 
Una y otra concepción se anclan en modelos teóricos distintos y responden a principios filosóficos diferentes. Pensar nuestras prácticas desde esos modelos y desde esos principios conlleva un posicionamiento ético. En este trabajo hemos presentado las consideraciones teóricas del enfoque históricocultural y, desde ella, hemos argumentado a favor de la opción de su modelo de evaluación, en la cual ésta forma una unidad con el aprendizaje y el desarrollo. Esperamos con estos argumentos contribuir a la indagación dialógica de esta propuesta en la comunidad de aprendizaje y practica que conformamos los educadores y las educadoras.

\section{Referencias}

Álvarez Arboleda, Lina María, Cardona Vázquez, Josymar, Moreno Torres, Mary Annette \& Rodríguez Arocho, Wanda Celeste. (2005). Una mirada crítica a la evaluación psicodiagnóstica. Ponencia presentada en el XXX Congreso Interamericano de Psicología, Buenos Aires, Argentina.

Álvarez Arboleda, Lina María, Moreno Torres, Mary Annette \& Rodríguez Arocho, Wanda Celeste. (2003). Evaluación neurocognoscitiva del Trastorno por Déficit de Atención e Hiperactividad. Perspectivas Psicológicas, 3 (4), 83-90.

Álvarez Méndez, Juan Manuel. (2001). Entender la didáctica, entender el curriculum. Madrid: Miño y Dávila Editores.

Álvarez Méndez, Juan Manuel. (2003). La evaluación a examen: Ensayos críticos. Madrid: Miño y Dávila Editores.

Álvarez Méndez, Juan Manuel. (2005). Evaluar para conocer, examinar para excluir (2da.ed.). Madrid: Ediciones Morata.

Arias Beatón, Guillermo. (2001). Evaluación y diagnóstico desde el enfoque históricocultural. Sao Paulo: Carnielo.

Artiles, Alfredo. (2003). Special education's changing identity: Paradoxes and dilemmas in views of culture and space. Harvard Educational Review, 73 (2), 164-202.

Baquero, Ricardo (2001). La educabilidad bajo sospecha. Cuaderno de Pedagogía Rosario, Año IV, (9), 71-85.

Baquero, Ricardo. (2006). Del individuo auxiliado al sujeto en situación. Algunos problemas en los usos de los enfoques socioculturales en educación. Revista Espacios en Blanco. Serie Indagaciones, (16), NEES/UNCPBA.

Baquero, Ricardo. (2009). Zona de desarrollo próximo, sujeto y situación: El problema de las unidades de análisis en la psicología educativa. Actualidades Investigativas en Educación, 9 (Especial). Instituto de Investigación de la Universidad de Costa Rica. 
Recuperado el 10 de febrero de 2010 de http://revista.inie.ucr.ac.cr/articulos/esp2009/zdp.php

Baquero, Ricardo, Dicker, Gabriela \& Frigerio, Gabriela. (2007). (Eds). Las formas de lo escolar. Buenos Aires: Del Estante Editorial.

Brooks, David. (2010). The underlying tragedy. New York Times. Recuperado el 14 de febrero de 2010 de http://www.nytimes.com/2010/01/15/opinion/15brooks.html

Bruner, Jerome. (1962). Prologue. Thought and Language. Cambridge, MA: MIT Press.

Chaklin, Seth. (2003). The zone of proximal development in Vygotsky's analysis of learning and instruction. En A. Kozulin, B. Gindis, V.S. Agueyev \& S.M. Miller (Eds.). Vygotsky's educational theory in cultural context (pp. 39-64). New York: Cambridge University Press.

Cole, Michael \& Distributed Literacy Consortium. The fifth dimension: An after school program built on diversity. New York: Sage Russell Foundation.

Cruz González, Damaris. (2009). Evaluación del aprendizaje: Retos para la tarea docente. Ponencia presentada en la Quincuagésimo Sexta Convención Anual de la Asociación de Psicología de Puerto Rico, Ponce, Puerto Rico.

D’Angelo, Ovidio. (2005). La subjetividad y la complejidad: Construcción y transformación individual y social. Ponencia presentada en la Convención Intercontinental de Psicología y Ciencias Sociales y Humanas HOMINIS'05. La Habana, Cuba.

Daniels, Harry. (2001). Vygotsky and pedagogy. London: Routledge.

del Río, Pablo \& Álvarez, Amelia. (1997). ¿Saber o comportarse? El desarrollo y la construcción de la directividad. En A. Álvarez (Ed.), Hacia un currículum cultural: La vigencia de Vygotski en la educación (pp.101-131). Madrid: Fundación Infancia y Aprendizaje.

del Río, Pablo \& Álvarez., Amelia. (2007). Inside and outside the zone of proximal development: An ecofunctional reading of Vygotsky. En H. Daniels, M.Cole \& J.V. Wertsch (Eds.), The Cambridge companion to Vygotsky. New York: Cambridge University Press.

Docentes de la Escuela 57, Baquero, Ricardo \& Greco, M. Beatriz. (2007). Un proyecto de no gradualidad: Variaciones para pensar la escuela y las prácticas. En Ricardo. Baquero, Gabriela Diker \& Graciela Frigerio, G. (Eds), Las formas de lo escolar (pp. 153-176). Buenos Aires: Del Estante Editorial.

Fariñas León, Gloria. (2005). Psicología, educación y sociedad: Un estudio sobre el desarrollo humano. La Habana: Editorial Félix Varela. 
Gindis, Boris. (2003). Remediation through education: Sociocultural theory and children with special needs. En A. Kozulin, B. Gindis, V.S. Agueyev \& S.M. Miller (Eds.), Vygotsky's educational theory in cultural context (pp. 200-223). New York: Cambridge University Press.

Hedegaard, Marianne. \& Chaklin, Seth. (2005). Radical-local teaching and learning: A cultural-historical approach. Denmark: Aarhaus University Press.

Kozulin, Alex. (2000). Instrumentos psicológicos: La educación desde la perspectiva sociocultura. Buenos Aires: Paidós.

Kozulin, Alex. (2003). Psychological tools and mediated learning. En A. Kozulin, B. Gindis, V.S. Agueyev \& S.M. Miller (Eds.), Vygotsky's educational theory in cultural context (pp. 15-38). New York: Cambridge University Press.

Kozulin, Alex \& Gindis, Boris. (2007). Sociocultural theory and education of children with special needs: From defectology to remedial pedagogy. En H. Daniels, M. Cole \& J. V. Wertsch (Eds), The Cambridge companion to Vygostky. New York: Cambridge University Press.

Lewin, Kurt. (1991). Epistemología comparada. Madrid: Editorial Tecnos.

Lidz, Carol \& Gindis, Boris. (2003). Dynamic assessment of evolving cognitive functions in children. En A. Kozulin, B. Gindis, V.S. Agueyev \& S.M. Miller (Eds.). Vygotsky's educational theory in cultural context (pp. 99-116). New York: Cambridge University Press.

Luria, Alexander Romanovich. (1976). Cognitive development: Its cultural and social foundations. MA: Harvard University Press.

Mitjans Martínez, Albertina. (2009). La perspectiva históricocultural y la educación especial: Contribuciones iniciales y desarrollos actuales. Actualidades en Investigación Educativa, 9 (Especial). Instituto de Investigación de la Universidad de Costa Rica. Recuperado el 10 de febrero de 2010 de http://revista.inie.ucr.ac.cr/articulos/esp2009/articulos.php

Moll, Luis. (1990). (Ed.). Vygotsky and education: Instructional implications and applications of sociohistorical psychology (pp.59-88). Cambridge, MA: Cambridge University Press.

Moll, Luis. (1997). Vygotski, la educación y la cultura en acción. En A. Álvarez (Ed.), Hacia un currículum cultural: La vigencia de Vygotski en la educación (pp.39-54). Madrid: Fundación Infancia y Aprendizaje.

Morin, Edgar. (1999). Los siete saberes necesarios para la educación. New York: Organización de las Naciones Unidas para la Educación, la Ciencia y la Cultura.

Morin, Edgar, Roger, Emilio \& Motta, Raúl .D. (2002). La educación en la era planetaria. Barcelona: Gedisa. 
Munné, Frederic (1995). Las teorías de la complejidad y sus implicaciones en las ciencias del comportamiento. Revista Interamericana de Psicología, 29, 1-12.

Munné, Frederic. (2004). El retorno de la complejidad y la nueva imagen de ser humano: Hacia una psicología compleja. Revista Interamericana de Psicología, 38, 23-32.

Munné, Frederic. (2005). ¿Qué es la complejidad? En F. Munné (Ed.). En Encuentros en Psicología Social: La complejidad en la psicología social y de las organizaciones, 3 (2), 6-18.

Portes, Pedro. (2005). Dismantling Educational Inequality: A Cultural-Historical Approach to Closing the Achievement Gap. New York, NY: Peter Lang.

Portes, Pedro \& Vadeboncoeur, Jennifer. (2003). Mediation in cognitive socialization: The influence of socioeconomic status. En A. Kozulin, B. Gindis, V.S. Agueyev \& S.M. Miller (Eds.), Vygotsky's educational theory in cultural context (pp. 371-392). New York: Cambridge University Press.

Rodríguez Arocho, Wanda Celeste. (1998). La valoración del funcionamiento cognoscitivo en la zona de desarrollo próximo. Psicología Contemporánea, 5 (2), 56-65.

Rodríguez Arocho, Wanda Celeste. (2000a). Interacción social y mediación semiótica en la teoría de desarrollo cognoscitivo de Lev S. Vygotsky, Perspectivas Psicológicas, 1 (1), 44-50.

Rodríguez Arocho, Wanda Celeste. (2000b). El tema de la conciencia en la psicología de Vygotski y la pedagogía de Freire: Implicaciones para la educación. En A. Villarini Jusino, D. Schipani \& F. Noriega (Eds.), Actas del 10mo. Encuentro Nacional de Educación y Pensamiento: Globalización, pensamiento crítico y pedagogía de la liberación (pp.178-192). Universidad de Puerto Rico: Proyecto para la Enseñanza de Destrezas de Pensamiento.

Rodríguez Arocho, Wanda Celeste. (2002). Herramientas culturales y transformaciones mentales: De los jeroglíficos a la internet. Ciencias de la Conducta, 17, 12-19.

Rodríguez Arocho, Wanda Celeste. (2006). El constructivismo: Una invitación al análisis de sus antecedentes, vertientes y críticas, Pedagogía, 39, 12-28.

Rodríguez Arocho, Wanda Celeste. (2007a). ¿Qué es la perspectiva históricocultural? Creecemos: Revista Hispano-americana de Educación y Pensamiento, 9 (1), 6776.

Rodríguez Arocho, Wanda Celeste. (2007b). El estudio de los procesos cognitivos en Puerto Rico: Antecedentes, actualidad y perspectivas. (2007). Revista Puertorriqueña de Psicología, 17, 515-550.

Rodríguez Arocho, Wanda Celeste. (2008). Los aportes de Lev S. Vygotski a la investigación educativa. Revista de Psicología, 4 (8), 43-60. 
Rodríguez Arocho, Wanda Celeste. (2009). El concepto de calidad educativa: Una mirada crítica desde el enfoque históricocultural. Ponencia presentada en el 10mo. Encuentro Internacional de Educación y Pensamiento, Centro de Convenciones, Cartagena, Colombia, 4 de mayo de 2009.

Rodríguez Arocho, Wanda Celeste. (2010). La Perspectiva Histórico-Cultural en la Formación Docente: Un examen de retos y posibilidades. Conferencia presentada en el 11 mo. Encuentro Internacional de Educación y Pensamiento, Santo Domingo, República Dominicana.

Rodríguez Arocho, Wanda Celeste \& Alom Alemán, Antoinette. (2009). El enfoque sociocultural en el diseño y construcción de una comunidad de aprendizaje. En Actualidades en Investigación Educativa, 9 (Especial). Revista electrónica del Instituto de Investigación de la Universidad de Costa Rica. Recuperado el 10 de febrero de 2010 de http://revista.inie.ucr.ac.cr/articulos/esp-2009/comunidad.php

Rogoff, Barbara. (2003). The cultural nature of human development. New York: Oxford University Press.

Scribner, Sylvia. (1990). Reflections on a model. The Quarterly Newsletter of the Laboratory of Comparative Human Cognition, 12 (2), 90-94.

Serrano-García, Irma. (2006) Mentorship: A power-ful relationship. Revista Pedagogía, 39 (1), 99-124.

Serrano-García, Irma (2009). Bases conceptuales y retos a la evaluación del aprendizaje. Ponencia en el panel Evaluación del aprendizaje: Retos para la tarea docente, Quincuagésimo Sexta Convención Anual de la Asociación de Psicología de Puerto Rico, Ponce, Puerto Rico.

Smith, Jonathan, Harré, Rom \& Luk Van Langenhove, L. (Eds.). (1995a). Rethinking psychology. London: Langenhove.

Smith, Jonathan., Harré, Rom \& Luk Van Langenhove, L. (Eds.). (1995b). Rethinking methods in psychology. London: Langenhove.

Valsiner, Jaan. (2007). Culture in minds and societies: Foundations of cultural psychology. Los Angeles: Sage Publications.

Van der Veer, Rene (1991). The idea of units of analysis. En S. Chaklin (Ed.). The theory and practice of cultural-historical psychology (pp. 93-106). Denmark: Aarhus University Press.

Vygotski, Lev S. (1927/1991). El significado histórico de la crisis en la psicología. En L. S. Vygotsky: Obras Escogidas, Tomo I (pp. 257-407). Madrid. Aprendizaje Visor.

Vygotski, Lev S. (1931a/1995). Historia del desarrollo de las funciones psíquicas superiores. Diagnóstico del desarrollo y clínica paidológica de la infancia difícil. En L. S. Vygotsky: Obras Escogidas, Tomo III (pp. 10-325). Madrid. Aprendizaje Visor. 
Vygotski, Lev S. (1931b/1997). Diagnóstico del desarrollo y clínica paidológica de la infancia difícil. En L. S. Vygotsky: Obras Escogidas, Defectología, Tomo V (pp. 275-338). Madrid. Aprendizaje Visor.

Vygotski, Lev S. (1932/1996). El problema de la edad. En L. S. Vygotsky: Obras Escogidas, Tomo IV (pp. 251-273). Madrid. Aprendizaje Visor.

Vygotski, Lev S. (1933/1996). La crisis de los siete años. En L. S. Vygotsky: Obras Escogidas, Tomo IV (pp. 377-386). Madrid. Aprendizaje Visor.

Vygotsky, Lev S. (1934/1993). Pensamiento y lenguaje. En L. S. Vygotsky: Obras Escogidas, Tomo II (pp. 9-348). Madrid. Aprendizaje Visor.

Wells, Gordon. (1999). Dialogic inquiry: Toward a sociocultural practice and theory of education. New York: Cambridge University Press.

Wertsch, James V. (1991). Voces de la mente. Madrid: Aprendizaje-Visor. 